\title{
Antibiotic Susceptibility Pattern and Extended Spectrum Beta Lactamase among Klebsiella pneumoniae isolates in a Tertiary Care Centre
}

\author{
B. U. Sunitha ${ }^{1 *}$ and B. V. Navaneeth ${ }^{2}$ \\ ${ }^{1}$ Department of Microbiology, Shridevi Institute of Medical Sciences and Research Hospital, \\ Sira Road, NH-04, Tumkur-572106, Karnataka, India \\ ${ }^{2}$ Department of Microbiology, ESIC-MC-PGIMSR, Rajajinagar, \\ Bengaluru-560010, India \\ *Corresponding author
}

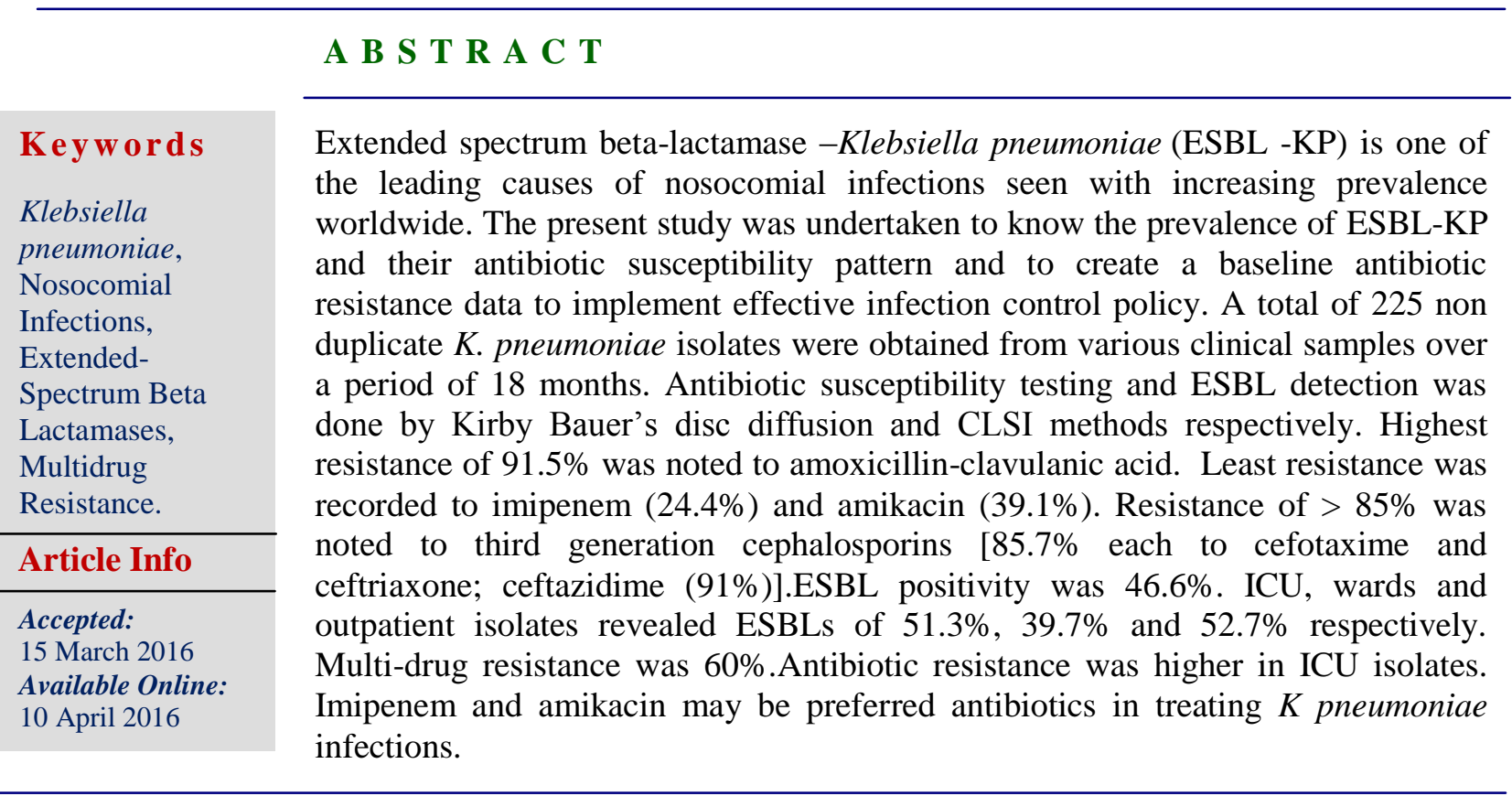

\section{Introduction}

Klebsiellae are opportunistic pathogens and can give rise to severe diseases such as septicemia, pneumonia, UTI and soft tissue infections. The hospitalized, immunocompromised patient with underlying diseases is the main target of these bacteria. The emergence and rapid spread of drug resistant Klebsiella pneumoniae isolates is becoming a serious antibiotic management problem causing a great concern worldwide. (Jemima et al., 2008)

$K$ pneumoniae is considered the most medically important Klebsiella species, causing $75 \%$ to $86 \%$ of hospital acquired infections (Hansen et al., 2004). Since the production of ESBL is frequently accompanied by broad-spectrum resistance, the ESBL positivity should be monitored 
closely as the emergence of those highly drug-resistant $K$. pneumoniae strains will pose a serious impact on the remaining therapeutic options (Ben-David et al., 2012) In a study based on the Tigecycline Evaluation and Surveillance Trial (TEST) global surveillance database, the rate of ESBL production was highest among the $K$. pneumoniae isolates collected in Latin America, followed by Asia / Pacific Rim, Europe, and North America (44.0\%, 22.4\%, $13.3 \%$ and $7.5 \%$, respectively). Thus the potential of drug resistant $K$. pneumoniae to be a global health problem is great and more intensive surveillance of drug resistance in $K$. pneumoniae isolates is necessary in order to provide information for the development of effective diagnostic methods and drugs against the same. Hence the present study was performed to know the susceptibility pattern of $K$ pneumoniae to various antibiotic groups and prevalence of ESBL strains in our hospital.

\section{Materials and Methods}

The study was conducted between November 2012 to April 2014 at ESIC-MC and PGIMSR, Rajajinagar, Bengaluru, a tertiary care 500 bed teaching hospital. Clinical samples like pus, urine, sputum, blood, miscellaneous (throat swabs, vaginal swabs, body fluids) from both out-patients and inpatients submitted to diagnostic microbiology were included. $K$ pneumoniae were isolated (only one isolate per patient included) and identified by standard methods. (Crichton, 2008)

\section{Antibiotic Susceptibility Testing [AST]}

Antibiotic susceptibility test was performed by Kirby- Bauer's disc diffusion method using commercially available antibiotic discs [Hi Media, Mumbai, India]. Antibiotic disc included were ceftazidime $[30 \mu \mathrm{g}]$, ceftazidime/clavulanicacid [30/10 $\quad$ g], cefoxitin $[30 \mu \mathrm{g}]$, cefotaxime $\left[\begin{array}{ll}30 & \mu \mathrm{g}\end{array}\right]$, cefoperazone $[75 \mu \mathrm{g}]$, cefoperazone $[75 \mu \mathrm{g}] /$ sulbactum $[10 \mu \mathrm{g}]$, ceftriaxone [30 $\mu \mathrm{g}]$, ciprofloxacin $[5 \mu \mathrm{g}]$, amikacin [30 $\mu \mathrm{g}]$, amoxicillin/ clavulanicacid [20/10 $\mu \mathrm{g}]$, aztreonam $[30 \mu \mathrm{g}]$, cefepime $[30 \mu \mathrm{g}]$, imipenem $[10 \mu \mathrm{g}]$, piperacillin $[100 \mu \mathrm{g}]$, piperacillin/tazobactum [100/10 $\mu \mathrm{g}]$, gentamicin $[10 \mu \mathrm{g}]$, trimethoprim/ sulphamethoxazole $[1.25 / 23.75 \mu \mathrm{g}]$.

A lawn of test pathogen prepared by evenly spreading 100 microliter inoculums with a sterilized swab onto Mueller Hinton agar plate. Antibiotic discs were gently and firmly placed on the agar plates, left at room temperature for 1 hour to allow diffusion of the antibiotics into the agar medium. The plates were then incubated at $37^{\circ} \mathrm{C}$ for 24 hours. If an antibiotic activity was present on the plates, it was indicated by an inhibition zone. The diameter of the inhibition zones was measured in millimeter at 24 hours using a measuring scale. An organism was interpreted as susceptible or resistant by comparing the zone of inhibition to standard chart.

\section{Screening for of ESBL}

According to Clinical and Laboratory Standards Institute (CLSI) guidelines ${ }^{[8]}$, strains showing zone of inhibition of $\leq 22$ $\mathrm{mm}$ for ceftazidime, $\leq 27 \mathrm{~mm}$ for cefotaxime, and $\leq 25 \mathrm{~mm}$ for ceftriaxone in Kirby-Bauer's disc diffusion method were selected for confirmatory tests of ESBL.

\section{ESBL Confirmatory Test}

\section{Phenotypic Confirmatory Disc Diffusion Test (PCDDT) for ESBL ${ }^{[9]}$}

ESBL production was confirmed among potential ESBL-producing isolates by phenotypic tests. Lawn culture of the organism was made and 3rd generation 
cephalosporin- ceftazidime $(30 \mu \mathrm{g})$ disc and ceftazidime + clavulinic acid $(30 \mu \mathrm{g}+10$ $\mu \mathrm{g})$ disc was placed $25 \mathrm{~mm}$ apart [Fig.1]. An isolate showing increase of $\geq 5 \mathrm{~mm}$ in zone of inhibition for ceftazidime + clavulinic acid compared to ceftazidime alone was confirmed as ESBL producer.

\section{Statistical Analysis}

Simple statistics to calculate percentage of antibiotic resistance in Klebsiella pneumoniae isolates were performed by entering the data into MicroSoft Excel and analysed. Statistical significance was assessed by calculating $\mathrm{P}$ value by Chisquare test.

\section{Results and Discussion}

A total of $225 \mathrm{~K}$ pneumoniae were isolated during the study period. Fifty five $(24.4 \%)$ were from outpatients, $72(32 \%)$ were from the intensive care unit and $98(43.5 \%)$ were from wards [Fig 2]. Eighty (35.6\%) isolates were from females and $145(64.4 \%)$ isolates were from males. Isolation from blood, pus, urine, sputum and miscellaneous was 18 (8\%), $50(22.2 \%), 53(23.6 \%), 72(32 \%)$ and $32(14.2 \%)$ respectively [Fig 3]. Isolates of $K$ pneumoniae revealed $46.6 \%$ of ESBLs. ICU, inpatients and outpatient isolates revealed ESBLs of $51.3 \%, 39.7 \%$ and $52.7 \%$ respectively.

Highest resistance of $91.5 \%$ was noted to amoxicillin-clavulanic acid. Least resistance was recorded to imipenem (24.4\%) and amikacin $(39.1 \%)$. Resistance of $>85 \%$ was noted to third generation cephalosporins [85.7\% each to cefotaxime and ceftriaxone; ceftazidime (91\%)]. Resistance to gentamicin, piperacillin-tazobactam, cefoperazone-sulbactam, ciprofloxacin, cotrimoxazole and cefipime was $52.8 \%$, $60.4 \%, 60.8 \%, 61.3 \%, 67.5 \%$ and $68 \%$ respectively (Table 1). Multi-drug resistance was found to be $60 \%$. Piperacillintazobactam, cefipime, gentamicin, amikacin and imipenem resistance among ESBL positive isolates were higher compared to ESBL negative isolates whereas cefoperazone-sulbactam, ciprofloxacin and co-trimoxazole resistance did not show significant ( $\mathrm{p}$ value $>0.5$ ) difference among positive and negative isolates.

Antibiotic-resistant $K$. pneumoniae has been a noteworthy nosocomial pathogen for over 4 decades encountering resistance to third generation cephalosporins (3GC) through ESBLs. ${ }^{[10]}$ In the present study, more than $85 \%$ isolates were resistant to $3 \mathrm{GC}$ and $68 \%$ percent were resistant to fourth generation cephalosporin (cefipime) and $46.6 \%$ were ESBL producers. Study from Punjab reveals $15.6 \%$ of $K$ pneumoniae as ESBL producers whereas ESBL production was $46.2 \%$ in $K$. pneumoniae across Karnataka The detection rates of ESBL-KP from different studies across Karnataka have been reported to vary from $9.6 \%$ (Bangalore) to $81.8 \%$ (Mangalore).

Recent study from SaudiArabia shows highest percentage of ESBLs were from suction tip followed by blood, urine, and pus samples (Gupta et al., 2007) and a similar reports have been presented by Gupta et al from India. (Babypadmini et al., 2004) Other Indian studies from Coimbatore (Ananthan et al., 2005) and Chandigarh on prevalence of ESBLs from urine and blood samples reports $40 \%$ and $69.2 \%$ respectively whereas sputum and urine isolates shows highest percentage of ESBLs in the present study. Prevalence of ESBL producers in any hospital depends upon various factors such detection methods used, antibiotic policy, the carriage rate among the hospital personnel, and the type of disinfectant used especially in the ICU. 
Table.1 Distribution of Antibiotic Resistance (\%) of K pneumoniae among different Patient Category

\begin{tabular}{|l|l|l|l|l|l|l|l|l|l|l|}
\hline \multirow{2}{*}{$\begin{array}{l}\text { Patient } \\
\text { category }\end{array}$} & \multicolumn{9}{|c|}{ Antibiotics } & CTX \\
\cline { 2 - 10 } & CAZ & CPZ & CPM & IM & AC & PTZ & AK & CF & COT \\
\hline OP( 55) & $45(81.8)$ & $48(87.2)$ & $44(80)$ & $35(63.6)$ & $8(14.5)$ & $46(86.6)$ & $28(50.9)$ & $14(25.4)$ & $26(47.2)$ & $28(50.9)$ \\
\hline IP (98) & $83(84.6)$ & $88(89.7)$ & $83(84.6)$ & $66(67.3)$ & $23(23.4)$ & $91(92.8)$ & $63(64.2)$ & $35(35)$. & $57(58.1)$ & $63(64.2)$ \\
\hline ICU(72) & $65(90.2)$ & $69(95.8)$ & $65(90.2)$ & $52(72.2)$ & $24(33.3)$ & $69(95.8)$ & $45(62.5)$ & $39(54.1)$ & $55(76.3)$ & $61(84.7)$ \\
\hline $\begin{array}{l}\text { Total } \\
(225)\end{array}$ & $193(85.7)$ & $205(91.1)$ & $192(85.3)$ & $153(68)$ & $55(24.4)$ & $206(91.5)$ & $136(60.4)$ & $88(39.1)$ & $138(61.3)$ & $152(67.5)$ \\
\hline
\end{tabular}

OP:outpatient, IP: inpatient, ICU :intensive care unit, CTX: cefotaxime, CAZ: ceftazidime, CPZ: cefoperazone, CPM: cefpirome, IM: imipenem, AC: amoxyclavulanic acid, PTZ: piperacillin-tazobactam, AK: amikacin, CF: ciprofloxacin, COT: co-trimoxazole ( Numbers in parentheses represent percentage)

Fig.1 ESBL Detection by Phenotypic Disc Diffusion Method

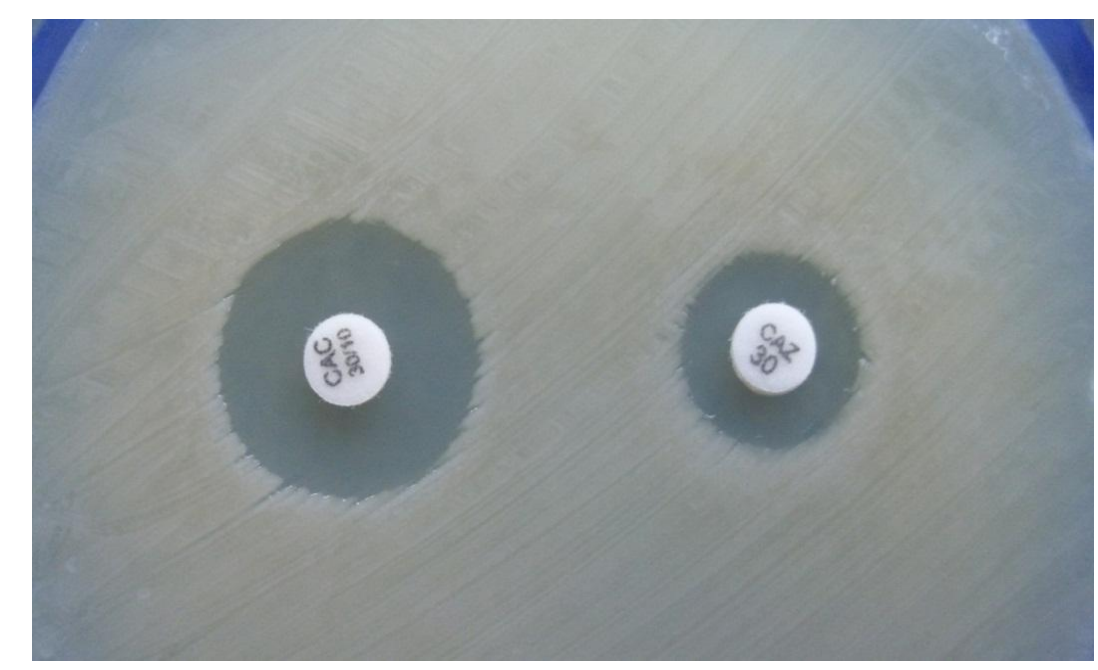


Int.J.Curr.Microbiol.App.Sci (2016) 5(4): 279-286
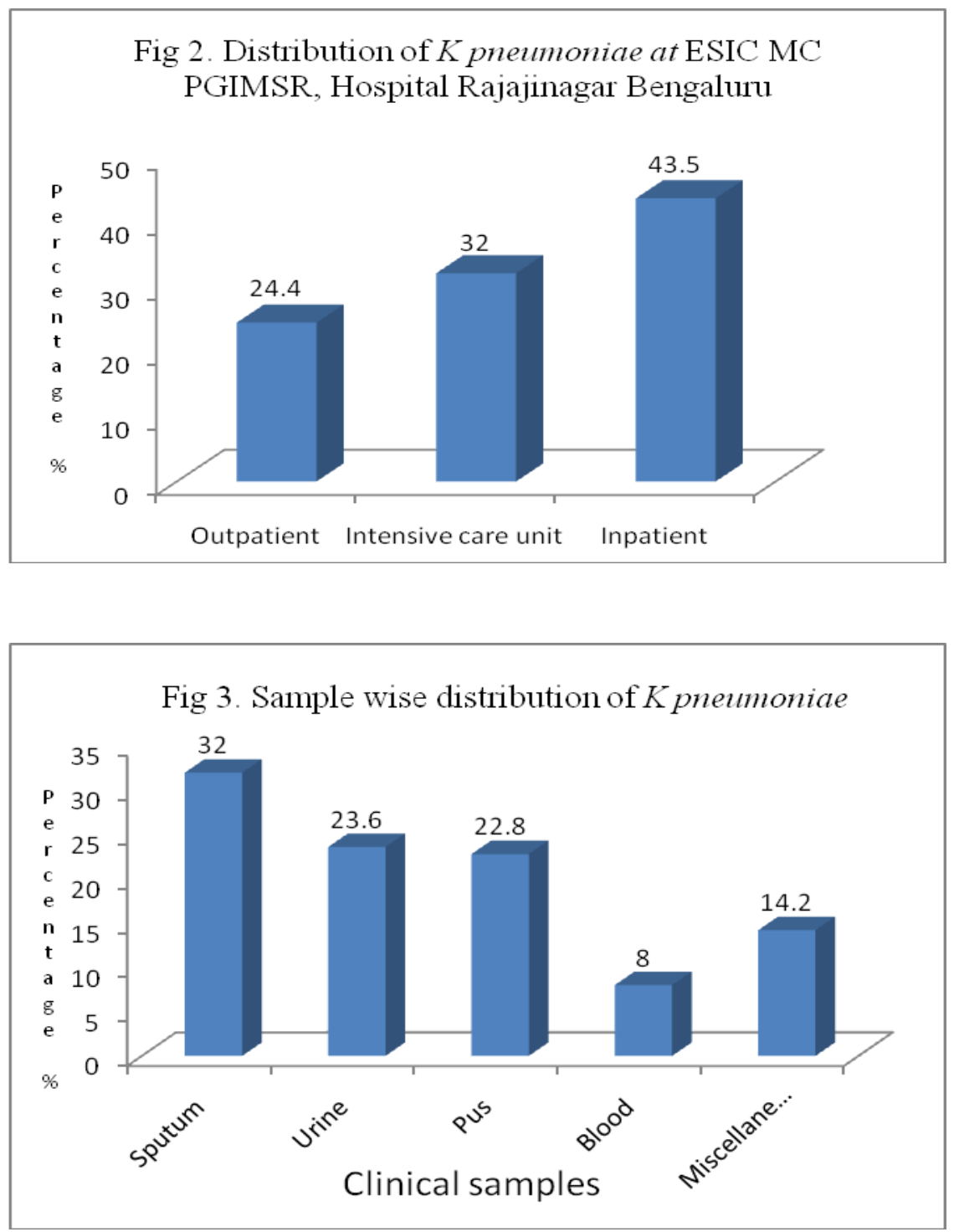
ESBL producing bacteria are typically associated with multidrug resistance and are most often encoded on plasmids, which can easily be transferred between isolates. (Podschun et al., 1998) Multidrug resistance ESBL-KP is major cause of nosocomial infections. The present study showsa multidrug resistance of $60 \%$ with high resistance to all antibiotics except imipenem and amikacin which correlates with other studies where least resistance was recorded to carbapenems and amikacin.

In conclusion, the present study showed that the prevalence of ESBL-producing $K$. pneumoniae was high among in-patients. Imipenem and amikacin could be useful antibiotics against these resistant isolates. Detection of ESBL-KP by phenotypic confirmatory disc diffusion test is simple and cost effective, can be incorporated into routine laboratory practice to control the spread of these infections and allow a proper therapeutic strategy. Further study is needed to detect other resistance mechanisms in these isolates.

\section{Acknowledgement}

I thank all the staff of department of Microbiology, ESIC MC and PGIMSR, Bengaluru for their help and support while conducting the study.

\section{References}

Jemima, S.A., Verghese, S. 2008. Molecular characterization of nosocomial CTX$M$ type beta-lactamase producing Enterobacteriaceae from a tertiary care hospital in south India. Indian J. Med. Microbiol., 4: 365-368.

Acheampong, D.O., Boamponsem, L.K. Occurrence and species distribution of Klebsiellaisolates: A case study at KomfoAnokye teaching hospital
(Kath) in Ghana. Adv. Appl. Sci., 2011; 2: 187-193.

Hansen, D.S., Aucken, H.M., Abiola, T., Podschun, R. Recommended test panel for differentiation of Klebsiellaspecies on the basis of a trilateral inter laboratory evaluation of 18 biochemical tests. J. Clin. Microbiol., 2004; 42: 3665-3669.

Ben-David, D., Kordevani, R., Keller, N., Tal, I., Marzel, A., et al. Outcome of carbapenem resistant Klebsiellapneumoniae bloodstream infections. Clin. Microbiol. Infect., 2012; 18: 54-60.

Reinert, R.R. Antimicrobial susceptibility among organisms from the Asia/ Pacific Rim, Europe and Latin and North America collected as part of TEST and the in vitro activity of tigecycline. J. Antimicrob. Chemother., 2007; 60: 1818-1829.

Crichton, P.B. Enterobacteriaceae:Escherichia, Klebsiella, Proteus and other genera. In Mackey and McCartney. Practical medical microbiology. $14^{\text {th }}$ ed. Editors-Collee JG, Fraser AG, Marmion BP, Simmons A. Elsevier 2008; 368-369.

Bauer, A.W., Kirby, W.N., Sherris, J.C., Truck, H. 1966. Antibiotic susceptibilty testing by a standardized single disc method. Am. J. Clin. Pathol., 1966; 45: 493-496.

ESBL screening Clinical Laboratory Standards Institute CLSI, "Performance standards for antimicrobial susceptibility testing," in Proceedings of the 16th International Supplement (M100S16), National Committee for Clinical Laboratory Standards, Wayne, Pa, USA, 2006

National Committee for Clinical Laboratory Standards NCCLS, 
Methods for Dilution Antimicrobial Susceptibility Tests for Bacteria that Grow Aerobically, Approved Standard M7-A5 and informational Supplement M100-S10, National Committee for Clinical Laboratory Standards, Wayne, Pa, USA, 2000.

Li, B., Yi, Y., Wang, Q., Woo, P.C.Y., Tan, L., Jing, H., et al. Analysis of drug resistance determinants in Klebsiellapneumoniae isolates from a tertiary-care hospital in Beijing, China. PLoS One. 2012; 7(7): e42280.

Oberoi, L., Singh, N., Sharma, P.M., Aggarwal A. ESBL, MBL and Ampc $\beta$ lactamases producing superbugs havoc in the intensive care units of Punjab India. J. Clin. Diag. Res, 2013; 70 (1): 70-73.

Rao, S.P.N., Rama, P.S., Gurushanthappa, V, Manipura, R, Srinivasan, K. Extended-spectrum beta-lactamases producing Escherichia coli and Klebsiellapneumoniae: multi-centric study across Karnataka. J Laboratory Physicians, 2014; 6: 713.

Bhat, P.V., Sarkar, A. Emergence and control of multidrug resistant organisms in small cities in India: A wake up call. Indian J. Med. Sci., 2011; 65:337-343.

Eshwarappa, M, Dosegowda, R, Aprameya, IV, Khan, MW, Kumar, PS, Kempegowda, $\quad$ P. Clinico-microbiological profile of urinary tract infection in south India. Indian J Nephrol 2011; 21:30-36. Kamath S, Mallaya S, Shenoy S. Nosocomial infections in neonatal intensive care units: Profile, risk factor assessment and antibiogram. Indian J Pediatr 2010; 77:37-39.

Abdel Rahim, K.A.A., Ali Mohamed, AM. Prevalence of extended spectrum $\beta$ lactamase-producing
Klebsiellapneumoniae in clinical isolates. Jundishapur $J$ Microbiol. 2014 November; 7(11): e17114.

Gupta V, Singla N, Chander J. Detection of ESBLs using third \& fourth generation cephalosporins in double disc synergy test. Indian J Med Res. 2007; 126(5):486-7.

Babypadmini S, Appalaraju B. Extended spectrum -lactamases in urinary isolates of Escherichia coli and Klebsiellapneumoniae - prevalence and susceptibility pattern in a tertiary care hospital. Indian J Med Microbiol. 2004; 22(3):172-4.

Ananthan S, Subha A. Cefoxitin resistance mediated by loss of a porin in clinical strains of Klebsiellapneumoniae and Escherichia coli. Indian $J$ Med Microbiol. 2005; 23(1):20-3.

Bradford PA. Extended-spectrum $\beta$ lactamases in the 21st century: characterization, epidemiology, and detection of this important resistance threat. Clinmicrobiol Rev 2001; 14: 933-951.

Podschun R, Ullmann U. Klebsiella spp. as nosocomial pathogens: epidemiology, taxonomy, typing methods and pathogenicity factors. Clin Microbiol Rev, 1998; 11: 589-603.

Goyal A, Prasad KN, Prasad A, Gupta S, Ghoshal U, Ayyagari A. Extended spectrum beta-lactamases in Escherichia coli \& Klebsiella pneumoniae \& associated risk factors. Indian J Med Res. 2009; 129: 695700. [PubMed: 19692752]

Somily AM, Habib HA, Absar MM, Arshad MZ, Manneh K, Al Subaie SS, et al. ESBL-producing Escherichia coli and Klebsiella pneumoniae at a tertiary care hospital in Saudi Arabia. J Infect DevCtries. 2014; 8:1129-36. [PubMed: 25212077]. 
Maina D, Makau P, Nyerere A, Revathi G. Antimicrobial resistance patterns in extended-spectrum $\quad \beta$-lactamase producing Escherichia coli and
Klebsiella pneumoniae isolates in a private tertiary hospital, Kenya. Microbiol Discov. 2013; 1: 5.

\section{How to cite this article:}

Sunitha, B. U., and Navaneeth, B. V. 2016. Antibiotic Susceptibility Pattern and Extended Spectrum Beta Lactamase among Klebsiella pneumoniae isolates in a Tertiary Care Centre. Int.J.Curr.Microbiol.App.Sci.5(4): 279-286. doi: http://dx.doi.org/10.20546/ijcmas.2016.504.032 